\title{
GMR
}

\section{Trans-translation ensures timely initiation of DNA replication and DnaA synthesis in Escherichia coli}

\author{
W. Wurihan, W. Wunier, H. Li, L.F. Fan and M. Morigen \\ School of Life Sciences, Inner Mongolia University, Hohhot, China \\ Corresponding authors: M. Morigen / L.F. Fan \\ E-mail: morigenm@hotmail.com / lifei.fan@imu.edu.cn
}

Genet. Mol. Res. 15 (3): gmr.15038407

Received January 8, 2016

Accepted March 18, 2016

Published August 29, 2016

DOI http://dx.doi.org/10.4238/gmr.15038407

Copyright (C) 2016 The Authors. This is an open-access article distributed under the terms of the Creative Commons Attribution ShareAlike (CC BY-SA) 4.0 License.

\begin{abstract}
The trans-translation pathway, mediated by the transfer messenger RNA (tmRNA; encoded by the ssrA gene) and the SmpB protein (tmRNA-binding protein expressed in Salmonella enterica), which is conserved in bacteria, is required for various cellular processes. A previous study has shown that trans-translation is required to ensure timely (non-delayed) dnaA transcription and consequent initiation of DNA replication in Caulobacter crescentus. In this study, we observed that initiation of chromosome replication was delayed in Escherichia coli lacking the $s m p B$ and/or ssrA genes ( $\Delta s s r A, \Delta s m p B$, or $\Delta s m p B \Delta s s r A$ mutants). We observed that the growth rate of the mutant cells was much slower than that of its wild-type counterpart. However, the delayed initiation of replication and slower growth in the $\triangle s s r A$ or $\triangle \operatorname{smp} B$ mutants were reversed by ectopic expression of tmRNA or SmpB. A synchronized $\triangle s m p B \Delta s s r A$ cell culture containing the $d n a C 2$ mutant allele showed delayed protein (total and DnaA) accumulation per cell; DnaA accumulation was also delayed in the $\Delta s m p B$. These
\end{abstract}


results indicated that absence of trans-translation leads to a delay in initiation of DNA replication, synthesis of total protein (including DnaA), and a decrease in E. coli growth rate. In summary, we propose that the trans-translation pathway is required to ensure timely initiation of replication, protein synthesis, and subsequent cell cycle progression.

Key words: Trans-translation; Replication initiation; dnaA expression; Cell cycle-dependent

\section{INTRODUCTION}

Trans-translation is a pathway employed by many bacteria to control the quality of translation (Keiler, 2008). One of the key components of trans-translation is the transfermessenger RNA (tmRNA) encoded by the ssrA gene, also named 10Sa RNA in Escherichai coli (Lee et al., 1978). tmRNA is a small RNA with tRNA and mRNA moieties, and is therefore functionally analogous to both tRNA and mRNA (Tyagi and Kinger, 1992; Komine et al., 1994). Another important component of this process is the SmpB protein, a tmRNA-binding protein found in Salmonella enterica (Karzai et al., 1999). A moving ribosome can be stalled unexpectedly or even programmatically during translation (Tenson and Ehrenberg, 2002). When a ribosome is stalled at the end of an mRNA that lacks a stop codon, tmRNA bound to SmpB is charged with alanine via the alanyl tRNA-synthetase (AlaRS), EF-Tu, and the ribosomal protein $\mathrm{S} 1$. The tmRNA/SmpB/EF-Tu complex then enters the A site of stalled ribosome with assistance from PrsA, SAF, RNase R, and tRNA ala , in order to transfer alanine from tmRNA to the nascent peptide chain. As a result, the nascent peptide chain is transferred from the original mRNA template to tmRNA. The mRNA moiety in the tmRNA molecule encodes the tag sequence of AANDENYALAA (Keiler et al., 1996), and the tagged peptide is then dissociated upon reaching the stop codon of tmRNA and subsequently degraded by ClpXP, RNase R, or other proteases (Gottesman et al., 1998; Levchenko et al., 2000; Shpanchenko et al., 2010).

The $s s r A$ and $\operatorname{smp} B$ genes are conserved in bacteria; trans-translation is required for different processes, including sporulation in Bacillus subtilis (Abe et al., 2008), symbiosis in Bradyrhizobium japonicum (Ebeling et al., 1991), pathogenesis in S. enterica (Julio et al., 2000) and Yersinia pseudotuberculosis (Okan et al., 2006), and cell cycle control in Caulobacter crescentus (Keiler and Shapiro, 2003). A previous study has shown that trans-translation is required to ensure that $d n a A$ transcription and consequent initiation of DNA replication in $C$. crescentus is not delayed (Cheng and Keiler, 2009). Mutations in the dnaA promoter partially suppress defects in the initiation of replication in the absence of trans-translation activity.

In this study, we investigated the possible involvement of trans-translation activity in ensuring the correct timing of protein synthesis and initiation of DNA replication; the latter appeared to be modulated by dnaA expression in a cell cycle-dependent manner.

\section{MATERIAL AND METHODS}

\section{Bacterial strains}

The E. coli K-12 bacterial strains used in this study are listed in Table 1 . The cam $^{\mathrm{R}}$ cassette was amplified by PCR using the pKD3 plasmid as the template and the primers

Genetics and Molecular Research 15 (3): gmr.15038407 
5'-del-ssrA-P1 and 3'-del-ssrA-P2 (Table 2). The amplified $c a m^{R}$ cassette was used to replace chromosomal ssrA in BW25113, using a previously described one-step chromosomal gene inactivation method (Datsenko and Wanner, 2000), resulting in a $\Delta s s r A::$ cam $^{R}$ mutant. The $k a n^{\mathrm{R}}$ cassette was amplified by PCR, using the pKD4 plasmid as the template and the 5'-del$\operatorname{smpB}$-P1 and 3'-del-ssrA-P2 primers (Table 2); this was used to simultaneously replace the chromosomal genes $\operatorname{smp} B$ and $s s r A$ in BW25113 by the method cited above, resulting in a $\triangle s m p B \Delta s s r A:: \mathrm{kan}^{R}$ double mutant. The $\operatorname{smp} B$ and $s s r A$ genes can be removed simultaneously, because of their proximity on the E. coli chromosome. The $d n a C 2:: t^{R} t^{R}$ allele was transduced using the P1 phage into BW25113 (wild-type); subsequently, the $\Delta s s r A:: \mathrm{cam}^{R}, \Delta s m p B:: \mathrm{kan}^{R}$, or $\Delta \operatorname{smp} B \Delta s s r A:: \mathrm{kan}^{R}$ allele was P1 transduced into BW25113dnaC2::tet $t^{R}$. Plasmid DNA was prepared using DH5 $\alpha$ as the host.

Table 1. Strains and plasmids used in the study.

\begin{tabular}{|c|c|c|}
\hline Strains & Genotype & Reference or source \\
\hline BW25113 & Wild-type rrnB3 $\triangle$ lacZ4787 hsdR514 $\Delta($ araBAD) $567 \Delta($ rhaBAD) 568 rph-l & Baba et al., 2006 \\
\hline MOR568 & $\mathrm{BW} 25113 \Delta \operatorname{smp} B:: \mathrm{kan}^{R}$ & Baba et al., 2006 \\
\hline MOR2363 & BW25113 $\Delta s r A::$ cam $^{R}$ & This study \\
\hline MOR2461 & BW25113 & This study \\
\hline MOR2471 & $\mathrm{BW} 25113 d n a C 2::$ tet $^{R}(\mathrm{Ts})$ & This study \\
\hline MOR2475 & 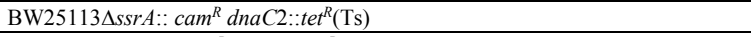 & This study \\
\hline MOR2476 & 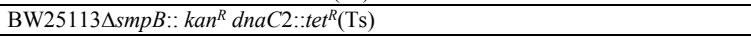 & This study \\
\hline MOR2477 & BW25113 $\Delta \operatorname{smp} B \Delta s s r A:: k^{R}{ }^{R}$ dnaC2::tet ${ }^{R}(\mathrm{Ts})$ & This study \\
\hline DH5 $\alpha$ & $\mathrm{F}^{-} \sup \mathrm{E} 44 \Delta l a c \mathrm{U} 169(\Delta l a c Z \Delta M 15)$ hsdR17 recA1 endA1 gyrA96 & New England Biolabs \\
\hline \multicolumn{3}{|c|}{ C } \\
\hline pKD3 & rep $_{\mathrm{R} 6 \mathrm{~K}} a m p^{R}$ FRT cam $^{R} \mathrm{FRT}$ & Datsenko and Wanner, 2000 \\
\hline pKD4 & rep $6 \mathrm{~K} a m p^{R}$ FRT $k a n^{R}$ FRT & Datsenko and Wanner, 2000 \\
\hline pKD46 & $r e p_{\mathrm{pSC} 101^{\mathrm{ts}}} a m p^{R} \mathrm{P}_{\text {araBAD }} \gamma \beta$ exo & Datsenko and Wanner, 2000 \\
\hline pUHE21-2lacI ${ }^{q}$ & rep $_{\mathrm{pMB} 1} a m p^{R}$ lacI $^{q}$ & Soncini et al., 1995 \\
\hline pUHE21-ssrA & $s s r A$ was inserted into pUHE21 at the BamHI and HindIII sites & This study \\
\hline pUHE21-smpB & $s m p B$ was inserted into pUHE21 at the BamHI and HindIII sites & This study \\
\hline pUHE21-smpB-ssrA & $\begin{array}{l}\text { smpB and ssrA genes with their intergenic region were inserted into pUHE21 at } \\
\text { the BamHI and HindIII sites. }\end{array}$ & This study \\
\hline
\end{tabular}

Table 2. Primers used in the study.

\begin{tabular}{|c|c|c|}
\hline Name & Sequence $\left(5^{\prime}-3^{\prime}\right)$ & Usage \\
\hline 5'-del-ssrA-P1 & $\begin{array}{l}\text { CTGGTCATGGCGCTCATAAATCTGGTATACTTACCTTTACACATT } \\
\text { GTGTAGGCTGGAGCTGCTTC }\end{array}$ & \multirow[t]{2}{*}{$\begin{array}{l}\text { To delete } s s r A \text { gene on chromosome } \\
\text { with 3'-del-ssrA-P2 }\end{array}$} \\
\hline 3'-del-ssrA-P2 & $\begin{array}{l}\text { GGACTTCATCGGATGACTCTGGTAATCACCGATGGAGAATTTCA } \\
\text { TATGAATATCCTCCTTAG }\end{array}$ & \\
\hline 5'-del-smpB-P1 & $\begin{array}{l}\text { GGGGTGTTTTCGATTTCAGATTACCGATGATTCACGACGCTTGTG } \\
\text { TAGGCTGGAGCTGCTTC }\end{array}$ & $\begin{array}{l}\text { To delete } \operatorname{smp} B \text { and } s s r A \text { gene on } \\
\text { chromosome with 3'-del-ssrA-P2 }\end{array}$ \\
\hline 5'-pUHE21-smpB & CGGGATCCGATTACCGATGATTCACGAC(BamHI) & \multirow{2}{*}{$\begin{array}{l}\text { To insert the } \operatorname{smp} B \text { gene at the BamHI } \\
\text { and HindIII sites of pUHE21 }\end{array}$} \\
\hline 3'-pUHE21-smpB & CCCAAGCTTCGCGGTGAGGAACTGGTC(HindIII) & \\
\hline 5'-pUHE21-ssrA & CGGGATCCAATCTGGTATACTTACC $($ BamHI $)$ & \multirow{2}{*}{$\begin{array}{l}\text { To insert the } s s r A \text { gene at the } B a m \mathrm{HI} \text { and } \\
\text { HindIII sites of pUHE } 21\end{array}$} \\
\hline 3'-pUHE21-ssrA & CCCAAGCTTCTCTGGTAATCACCGATGG(HindIII) & \\
\hline
\end{tabular}

\section{Growth conditions}

Bacteria were cultured in ABTGcasa medium (Morigen et al., 2005; Yao et al., 2015) at $37^{\circ} \mathrm{C}$; additionally, the cultures were incubated at $30^{\circ}$ and $42^{\circ} \mathrm{C}$ for synchronization of $d n a C 2$ cells. The culture medium was supplemented with antibiotics when required (ampicillin, chloramphenicol, tetracycline, and/or kanamycin at final concentrations of $100,30,15$, and $50 \mu \mathrm{g} / \mathrm{mL}$ ). 


\section{Plasmid construction}

All plasmids used in this study are listed in Table 1. The ssrA gene was amplified by PCR using the wild-type chromosome as the template and the 5'-pUHE21-ssrA and 3'-pUHE21ssrA primers; this was subsequently inserted into pUHE21-2lacI ${ }^{\mathrm{q}}$ at the BamHI and HindIII sites, resulting in the pUHE21-ssrA plasmid, which expresses the $s s r A$ RNA. $s m p B$ was amplified by PCR at its native promoter region using the 5'-pUHE21-smpB and 3'-pUHE21-smpB primers, or at a region including the $\operatorname{smp} B$ and $s s r A$ genes using the 5'-pUHE21-smpB and 3'-pUHE21-ssrA primers, using the wild-type chromosomal DNA as the template. The resultant fragment from each PCR cycle was inserted into the pUHE21-2lacI ${ }^{q}$ plasmid at the BamHI and HindIII sites, respectively, resulting in the pUHE21-smpB and pUHE21-smpB-ssr $A$ plasmids.

\section{Flow cytometry}

The cells were exponentially grown in $\mathrm{ABTG}$ casa medium at $37^{\circ} \mathrm{C}$ up to an $\mathrm{OD}_{450}$ of 0.15 ; subsequently, the cells were treated with $300 \mu \mathrm{g} / \mathrm{mL}$ rifampicin and $10 \mu \mathrm{g} / \mathrm{mL}$ cephalexin for 4-5 generations in order to allow for the completion of the ongoing rounds of replication: rifampicin inhibits the initiation of replication by preventing transcription, while cephalexin inhibits cell division (Skarstad et al., 1986; Boye and Løbner-Olesen, 1991). In the presence of these drugs, the cells express an integral numbers of chromosomes, representing the number of origins per cell at the time of addition (of the drugs) (Skarstad et al., 1986). One milliliter aliquots of rifampicin- and cephalexin-treated cells were harvested, washed, and resuspended in $100 \mu \mathrm{L}$ TE buffer, and fixed by adding $1 \mathrm{~mL} 77 \%$ ethanol. The fixed cells were stained with Hoechst 33258 (Invitrogen, Carlsbad, CA, USA) as described previously (Liu et al., 2014), and subsequently analyzed with a flow cytometer (BD Biosciences, Franklin Lakes, NJ, USA). The average DNA content/cell ratio was determined as the average Hoechst fluorescence per cell. The standard sample was prepared as described in a previous study (Morigen et al., 2003).

\section{Synchronization of the $d n a C 2$ cells}

BW25113dnaC2 cells (and its derivatives) showing exponential growth in ABTGcasa medium at the permissive temperature $\left(30^{\circ} \mathrm{C}\right)$ were cultured at a non-permissive temperature $\left(42^{\circ} \mathrm{C}\right)$ for $2 \mathrm{~h}$; after which the cells were synchronized at a stage prior to the initiation of chromosomal replication (Carl, 1970; Withers and Bernander, 1998).

\section{Determination of the total protein content per cell}

Cell cultures $(4.5 \mathrm{~mL})$ were harvested at the indicated time points after synchronization by centrifugation at $4^{\circ} \mathrm{C}$, washed in $1 \mathrm{~mL}$ TE buffer, resuspended in $100 \mathrm{~mL}$ TE buffer containing $1 \%$ sodium dodecyl sulfate (SDS) and glycerol, and finally boiled for 5 min. Total protein content in the $4.5 \mathrm{~mL}$ cell extract was determined using a standard BCA kit (Thermo Fisher Scientific, Waltham, MA, USA) according to the manufacturer instructions. The number of cells in the cell cultures (fixed volume) harvested at the various time points were determined by plating a series of dilutions of the cultures on LB agar plates with the requisite antibiotics, and counting the colonies formed on the next day. The protein content and cell count in the $4.5-\mathrm{mL}$ culture (at each time point) was used to calculate the protein concentration per cell.

Genetics and Molecular Research 15 (3): gmr.15038407 


\section{Western blotting and determination of DnaA protein content per cell}

The cell extracts were separated by $12 \%$ SDS-polyacrylamide gel electrophoresis $(40 \mathrm{~mA}, 2-3 \mathrm{~h})$ for western blot analysis. Subsequently, the DnaA concentration and the DnaA content per cell was determined using a DnaA-antibody and an ECF fluorescence kit (Amersham Biosciences, Amersham, UK) as described previously (Liu et al., 2014).

\section{RESULTS}

\section{Absence of trans-translation delays initiation of chromosomal replication}

The tmRNA and SmpB proteins are key components of the trans-translation process. The deletion of the $s s r A$ or/and $s m p B$ genes has been previously shown to delay initiation of replication in C. crescentus (Keiler and Shapiro, 2003). In order to determine if transtranslation exerts a similar effect in $E$. coli, we developed $\Delta s s r A, \triangle s m p B$, and $\triangle s m p B \Delta s s r A$ mutant cells and monitored the replication pattern of cells lacking tmRNA, SmpB, or both by flow cytometry. Wild-type, $\Delta s s r A, \Delta \operatorname{smp} B$, or $\Delta s m p B \Delta s s r A E$. coli cells in the exponential phase of growth were treated with rifampicin and cephalexin for 4-5 generations. Therefore, the number of chromosomes per cell indicates the number of origins per cell after drug treatment (Skarstad et al., 1986). The wild-type culture was chiefly composed of 4 -chromosome cells (65\%); the remaining cells were composed of 2 chromosomes $(10 \%)$ or 8 chromosomes. The cell mass of this culture doubled every $33 \mathrm{~min}$ and the average number origins per cell was 4.4 (Figure 1) at the permissive culture conditions. In comparison, the $\triangle s s r A, \triangle s m p B$, and $\Delta s m p B \Delta s s r A$ mutant cell cultures were composed of a slightly higher number of 2-chromosome cells (and a lower number of 4-chromosome cells) and a lower average number of origins per cell (3.8-4.1); moreover, the doubling time (40-55 min) of these cultures was also seen to be higher (Figure 1). These results indicate that deletion of the $s s r A$ or $\operatorname{smp} B$ genes, or both, results in delayed initiation of chromosomal replication and slow growth. This in turn suggested that the absence of trans-translation delays the initiation of chromosomal replication, and subsequently, cell division, consistent with the mechanism previously reported in C. crescentus (Keiler and Shapiro, 2003).

\section{Delay in initiation of replication in the $\Delta s s r A$ and $\Delta s m p B$ mutants is reversed by ectopic expression of tmRNA and SmpB}

The plasmids pUHE21-ssrA (pssrA), pUHE21-smpB (psmpB), and pUHE21-smpB$s s r A$ (psmpB-ssrA), which ectopically express tmRNA, SmpB, or both tmRNA and SmpB, respectively, under IPTG induction, were used to investigate the possible rescue of delayed initiation of replication in the absence of trans-translation. The pssrA, psmpB, and psmpB$s s r A$ plasmids were subsequently introduced to $\triangle s s r A, \triangle s m p B$, or $\triangle s m p B \Delta s s r A$ mutant cells, respectively. The resulting cells were cultured in ABTGcasa medium up to the exponential phase of growth, and tmRNA and/or SmpB expression was subsequently induced with IPTG (final concentration $0.5 \mathrm{mM}$ ). The cells were then treated with rifampicin and cephalexin and analyzed by flow cytometry. We discovered that $\Delta s s r A$ or $\Delta s m p B$ expressing tmRNA or SmpB showed a wild-type-like replication pattern and growth rate (Figure 2); however, tmRNA and SmpB co-expression in the psmpB-ssrA plasmid-containing mutant cells did not induce any reversal in the delay in initiation of replication, because of an unknown reason. 


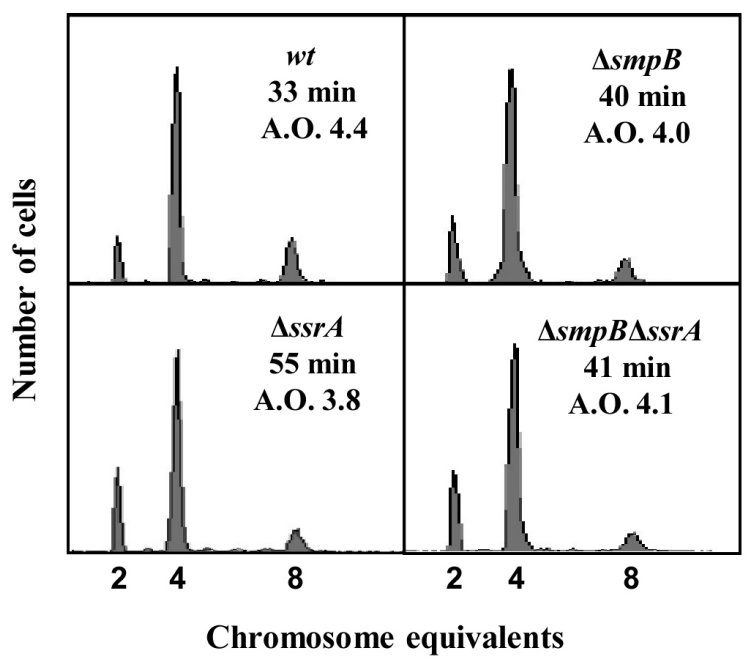

Figure 1. Absence of trans-translation delays the initiation of chromosome replication. Wild-type, $\Delta s s r A, \Delta s m p B$, and $\triangle s s r A \Delta s m p B$ mutant cells at the exponential phase of growth in the ABTGcasa medium at $37^{\circ} \mathrm{C}$ were treated for 4-5 generations with rifampicin and cephalexin to inhibit replication initiation and cell division, while allowing the completion of the ongoing replication cycles. The cells were then fixed in $70 \%$ ethanol, stained with Hoechst 33258 for $30 \mathrm{~min}$, and analyzed by flow cytometry. The $\mathrm{x}$ - and $\mathrm{y}$-axes indicate chromosome equivalents per cell and the number of measured cells, respectively. Each measurement includes 10,000 cells. A.O. $=$ average number of origins per cell, as described in a previous study (Liu et al., 2014). The doubling time and genotype of cells are also shown.

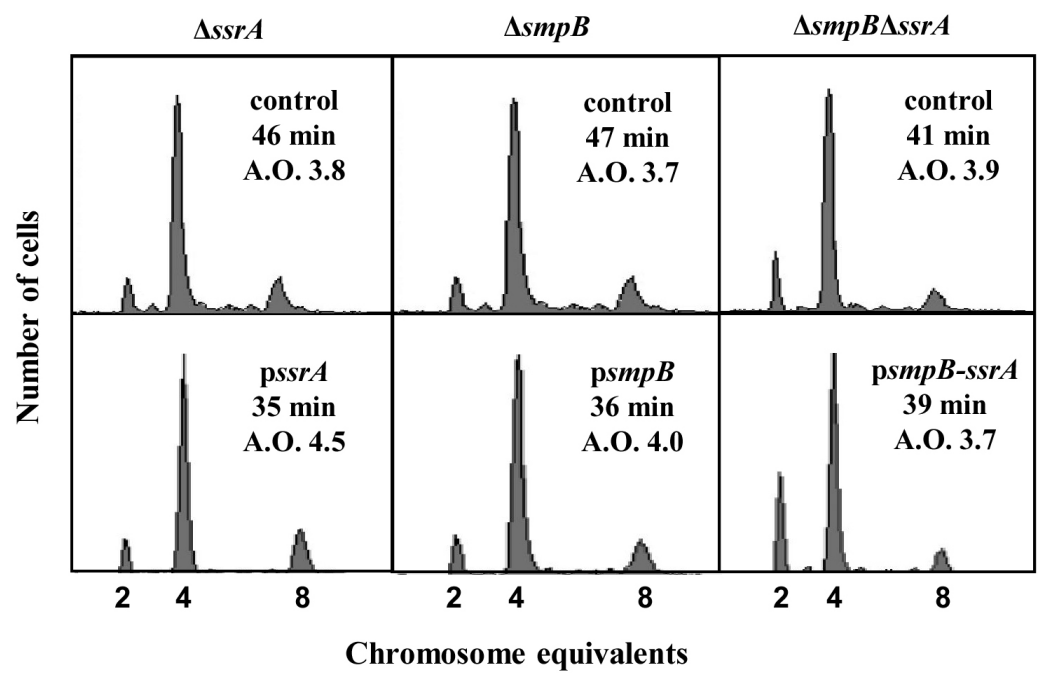

Figure 2. Ectopic expression of tmRNA or SmpB reverses the delayed initiation and slow growth of $\triangle s s r A$ and $\triangle s m p B$ mutant. $\triangle s s r A, \triangle s m p B$, and $\triangle s s r A \Delta s m p B$ mutant cells, carrying the pUHE21-ssrA, pUHE21-smpB, and pUHE21-smpB-ssrA plasmids, in the exponential phase of growth in ABTGcasa medium at $37^{\circ} \mathrm{C}$ were treated for 4-5 generations with rifampicin and cephalexin, collected, fixed in 70\% ethanol, stained with Hoechst 33258 for $30 \mathrm{~min}$, and analyzed by flow cytometry. The $\mathrm{x}$ - and y-axes indicate the chromosome equivalents per cell and the number of measured cells, respectively. Each measurement includes 10,000 cells. A.O. = average number of origins per cell. The doubling time of the cells is also shown.

Genetics and Molecular Research 15 (3): gmr.15038407 


\section{Lack of trans-translation delays DnaA expression}

The initiator protein DnaA, encoded by the $d n a A$ gene, is a determinant for replication initiation (Braun et al., 1985; Løbner-Olesen et al., 1989); dnaA transcription is delayed in the C. crescentus $\triangle$ ssrA mutant. Therefore, it is reasonable to question whether the expression of DnaA is delayed in the absence of trans-translation during the E. coli cell cycle progression. In order to address this question, dnaC2 mutant cells, which can be synchronized during the B-period (before initiation of chromosome replication) via a temperature shift (Carl, 1970; Withers and Bernander, 1998), were utilized. BW25113dnaC2 cells, or its derivative cells expressing the $\Delta s s r A, \Delta s m p B$, or $\triangle s m p B \Delta s s r A$ mutations, in the exponential phase of growth were shifted from a permissive temperature $\left(30^{\circ} \mathrm{C}\right)$ to a non-permissive temperature $\left(42^{\circ} \mathrm{C}\right)$ condition (Figure 3A). This stops a new round of initiation; however, the ongoing rounds of DNA synthesis and cell division continue, resulting in a single replicated chromosome being expressed in all cells after $120 \mathrm{~min}$ at the non-permissive temperature. Shifting the cell culture back to the permissive temperature leads to all cells initiating replication in a synchronous manner. Cell samples were taken at various time points (Figure 3) after shifting back to the permissive temperature; subsequently, the total protein content, cell count, and DnaA concentration was determined in a fixed culture volume. Protein production (quantified by amount per cell) in the wild-type cells peaked after culturing for $90 \mathrm{~min}$ in the permissive temperature, and decreased immediately afterward. $\Delta s s r A$ mutant cells showed a similar fluctuation in protein production (Figure 3B). Protein production (total amount per cell) in the $\triangle \operatorname{smp} B$ cells followed a similar pattern as the wild-type cells (peak at the 90-min time point); however, these cells produced proteins at the peak level for approximately $60 \mathrm{~min}$ before downregulating the protein production (Figure 3B). On the other hand, $\triangle \operatorname{smp} B \Delta s s r A$ mutant cells showed a further delay in the total protein synthesis per cell (Figure 3B). These results suggested that the time-frame for general protein synthesis requires trans-translation.

DnaA protein content per cell was monitored by western blotting; in this process, we detected the DnaA concentration in the total protein samples taken at different time points during cell cycle progression in order to calculate the relative DnaA content per cell. The DnaA content per cell in the wild-type and $\triangle s s r A$ cells peaked after $90 \mathrm{~min}$ at the permissive temperature, decreasing immediately afterward, in agreement with the fluctuation of total protein content during the cell cycle (Figure 3C). However, the peak DnaA content per cell in the $\triangle s m p B$ and $\triangle s m p B \Delta s s r A$ mutant cells was observed after 120 and $150 \mathrm{~min}$ in the permissive temperature, respectively (Figure 3C). These results indicated that DnaA accumulation could be delayed in the absence of trans-translation.

\section{DISCUSSION}

The initiation of chromosome replication in the $\Delta s s r A, \Delta s m p B$ and $\triangle \operatorname{smp} B \Delta s s r A$ mutant cells was delayed relative to the wild-type cells (Figure 1); moreover, this delay was reversed by the ectopic expression of the $s s r A$ or $s m p B$ gene (Figure 2). Surprisingly, tmRNA and SmpB co-expression (due to the insertion of the psmpB-ssrA plasmid) did not reverse the delay in replication initiation in the $\triangle \operatorname{smp} B \Delta s s r A$ cells. This could be attributed to the lack of functionality or incorrect expression of the co-expressed tmRNA or/and SmpB.

Genetics and Molecular Research 15 (3): gmr.15038407 
A

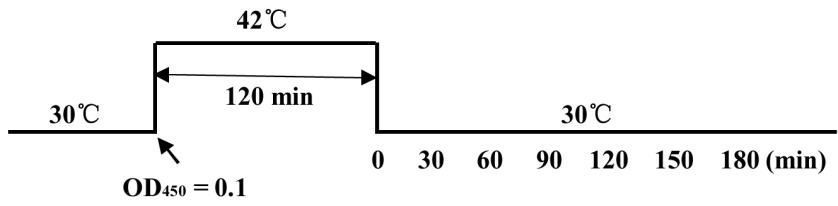

B

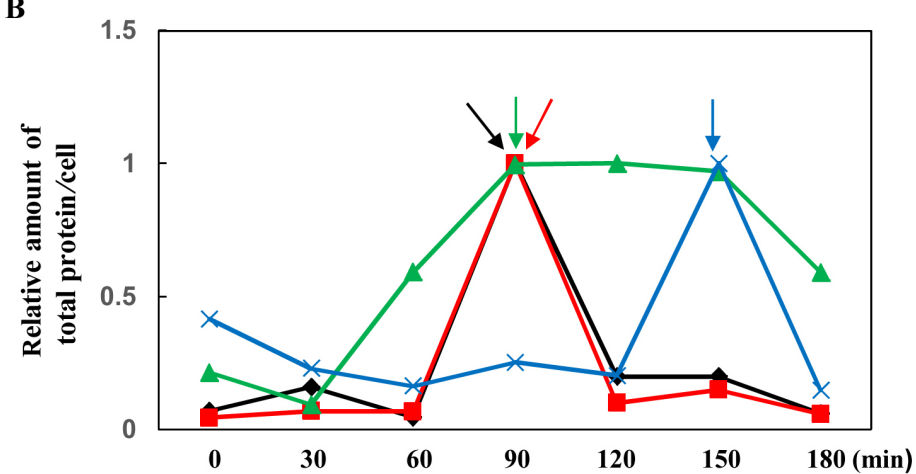

C

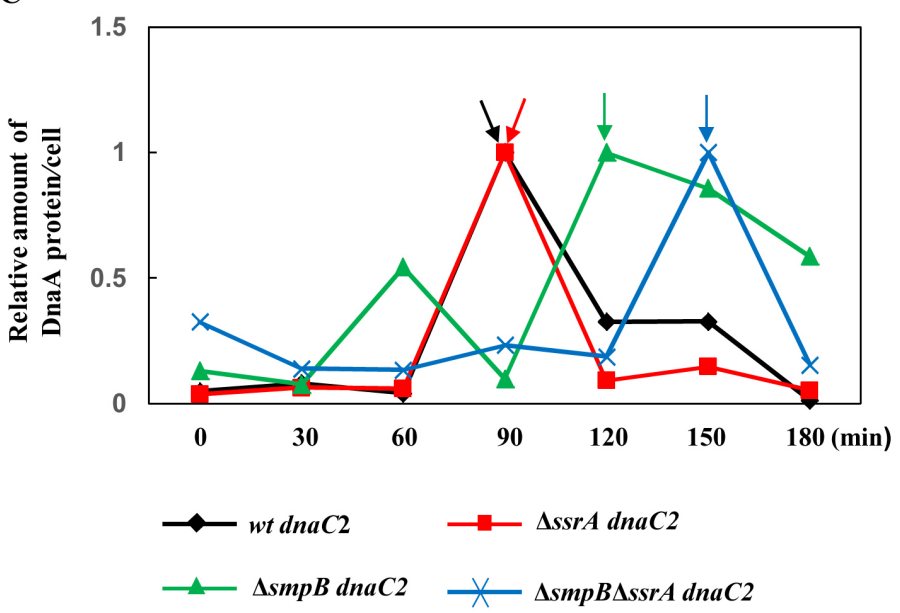

Figure 3. Protein synthesis and accumulation of DnaA per cell are delayed in the absence of trans-translation. A. Cells carrying the $d n a C 2$ allele in the exponential phase of growth in the ABTGcasa medium were shifted from the permissive temperature $\left(30^{\circ} \mathrm{C}\right)$ to the non-permissive temperature $\left(42^{\circ} \mathrm{C}\right)$; at this temperature, the DnaC2 mutant was inactivated, thereby inhibiting the initiation of replication at oriC. The cells were synchronized after $120 \mathrm{~min}$ at $42^{\circ} \mathrm{C}$. The synchronized cells were shifted to the permissive temperature and sampled at the indicated time intervals. B. Total protein content per cell was determined as described in Material and Methods. The x- and $y$-axes indicate time points at which the cell samples were taken and the total protein content at the indicated time points relative to the highest protein content per cell, respectively. The arrows indicate the peaks in accumulation of total protein per cell. The values are the average of three experiments. C. DnaA protein content per cell was determined as described in Material and Methods. The DnaA concentration was determined by western blotting, and the amount of protein cell was calculated. The relative DnaA content per cell was obtained by comparing the DnaA content per cell at each time point to the highest amount of DnaA per cell. The values are the average of three experiments. The $\mathrm{x}$ - and $\mathrm{y}$-axes indicate the sampling times and the relative amount of DnaA per cell. The arrows indicate the peaks in DnaA accumulation. Black, red, green, and blue are representative of wtdnaC2, $\triangle s s r A d n a C 2$, $\triangle \operatorname{smp} B d n a C 2$, and $\triangle \operatorname{smp} B \Delta s s r A d n a C 2$, respectively.

Genetics and Molecular Research 15 (3): gmr.15038407 
However, the growth rate of the $\triangle s s r A, \Delta s m p B$ and $\triangle s m p B \Delta s s r A$ mutant cells was slower than that of the wild-type cells. Moreover, total and DnaA protein accumulation in individual $\triangle s m p B \triangle s s r A$ mutant cells was delayed with respect to that in the wild-type cells (Figure 3). Therefore, we concluded that the trans-translation pathway ensures timely DnaA protein synthesis, which assists in the timely progression of the E. coli cell cycle. These conclusions are in agreement with those of a previous report, wherein trans-translation was shown to ensure timely $d n a A$ transcription, and consequent initiation of DNA replication in $C$. crescentus (Cheng and Keiler, 2009).

The trans-translation pathway is conserved in all bacteria, with the reactions occurring over 13,000 times per cell division in E. coli cells in the exponential phase of growth (Moore and Sauer, 2005). Clearly, the trans-translation pathway plays a major role in various aspects of the cell cycle. Interestingly, eukaryotic cells express a similar pathway in the form of the ribosome quality control complex, whose Rqc2p and $60 \mathrm{~S}$ ribosomal subunits mediate the mRNA-independent elongation of nascent chains (Shen et al., 2015).

\section{Conflicts of interest}

The authors declare no conflict of interest.

\section{ACKNOWLEDGMENTS}

Research supported by grants from the National Natural Science Foundation of China (NSFC grant \#31560245 to Morigen) and the Program of Higher-Level Talents of Inner Mongolia University (SPH-IMU grant \#Z20090107 to Morigen).

\section{REFERENCES}

Abe T, Sakaki K, Fujihara A, Ujiie H, et al. (2008). tmRNA-dependent trans-translation is required for sporulation in Bacillus subtilis. Mol. Microbiol. 69: 1491-1498. http://dx.doi.org/10.1111/j.1365-2958.2008.06381.x

Baba T, Ara T, Hasegawa M, Takai Y, et al. (2006). Construction of Escherichia coli K-12 in-frame, single-gene knockout mutants: the Keio collection. Mol. Syst. Biol. 2: 2006.0008.

Boye E and Løbner-Olesen A (1991). Bacterial growth control studied by flow cytometry. Res. Microbiol. 142: 131-135. http://dx.doi.org/10.1016/0923-2508(91)90020-B

Braun RE, O'Day K and Wright A (1985). Autoregulation of the DNA replication gene dnaA in E. coli K-12. Cell 40: 159-169. http://dx.doi.org/10.1016/0092-8674(85)90319-8

Carl PL (1970). Escherichia coli mutants with temperature-sensitive synthesis of DNA. Mol. Gen. Genet. 109: 107-122. http://dx.doi.org/10.1007/BF00269647

Cheng L and Keiler KC (2009). Correct timing of dnaA transcription and initiation of DNA replication requires trans translation. J. Bacteriol. 191: 4268-4275. http://dx.doi.org/10.1128/JB.00362-09

Datsenko KA and Wanner BL (2000). One-step inactivation of chromosomal genes in Escherichia coli K-12 using PCR products. Proc. Natl. Acad. Sci. USA 97: 6640-6645.http://dx.doi.org/10.1073/pnas.120163297

Ebeling S, Kündig C and Hennecke H (1991). Discovery of a rhizobial RNA that is essential for symbiotic root nodule development. J. Bacteriol. 173: 6373-6382.

Gottesman S, Roche E, Zhou Y and Sauer RT (1998). The ClpXP and ClpAP proteases degrade proteins with carboxyterminal peptide tails added by the SsrA-tagging system. Genes Dev. 12: 1338-1347. http://dx.doi.org/10.1101/ gad.12.9.1338

Julio SM, Heithoff DM and Mahan MJ (2000). ssrA (tmRNA) plays a role in Salmonella enterica serovar Typhimurium pathogenesis. J. Bacteriol. 182: 1558-1563. http://dx.doi.org/10.1128/JB.182.6.1558-1563.2000

Karzai AW, Susskind MM and Sauer RT (1999). SmpB, a unique RNA-binding protein essential for the peptide-tagging activity of SsrA (tmRNA). EMBO J. 18: 3793-3799. http://dx.doi.org/10.1093/emboj/18.13.3793

Genetics and Molecular Research 15 (3): gmr.15038407 
Keiler KC (2008). Biology of trans-translation. Annu. Rev. Microbiol. 62: 133-151. http://dx.doi.org/10.1146/annurev. micro.62.081307.162948

Keiler KC and Shapiro L (2003). TmRNA is required for correct timing of DNA replication in Caulobacter crescentus. $J$. Bacteriol. 185: 573-580. http://dx.doi.org/10.1128/JB.185.2.573-580.2003

Keiler KC, Waller PR and Sauer RT (1996). Role of a peptide tagging system in degradation of proteins synthesized from damaged messenger RNA. Science 271: 990-993. http://dx.doi.org/10.1126/science.271.5251.990

Komine Y, Kitabatake M, Yokogawa T, Nishikawa K, et al. (1994). A tRNA-like structure is present in 10Sa RNA, a small stable RNA from Escherichia coli. Proc. Natl. Acad. Sci. USA 91: 9223-9227. http://dx.doi.org/10.1073/ pnas.91.20.9223

Lee SY, Bailey SC and Apirion D (1978). Small stable RNAs from Escherichia coli: evidence for the existence of new molecules and for a new ribonucleoprotein particle containing 6S RNA. J. Bacteriol. 133: 1015-1023.

Levchenko I, Seidel M, Sauer RT and Baker TA (2000). A specificity-enhancing factor for the ClpXP degradation machine. Science 289: 2354-2356. http://dx.doi.org/10.1126/science.289.5488.2354

Liu F, Qimuge, Hao J, Yan H, et al. (2014). AspC-mediated aspartate metabolism coordinates the Escherichia coli cell cycle. PLoS One 9: e92229. http://dx.doi.org/10.1371/journal.pone.0092229

Løbner-Olesen A, Skarstad K, Hansen FG, von Meyenburg K, et al. (1989). The DnaA protein determines the initiation mass of Escherichia coli K-12. Cell 57: 881-889. http://dx.doi.org/10.1016/0092-8674(89)90802-7

Moore SD and Sauer RT (2005). Ribosome rescue: tmRNA tagging activity and capacity in Escherichia coli. Mol. Microbiol. 58: 456-466. http://dx.doi.org/10.1111/j.1365-2958.2005.04832.x

Morigen M, Løbner-Olesen A and Skarstad K. (2003). Titration of the Escherichia coli DnaA protein to excess datA sites causes destabilization of replication forks, delayed replication initiation and delayed cell division. Mol. Microbiol. 50: 349-362.

Morigen M, Molina F and Skarstad K (2005). Deletion of the datA site does not affect once-per-cell-cycle timing but induces rifampin-resistant replication. J. Bacteriol. 187: 3913-3920.

Okan NA, Bliska JB and Karzai AW (2006). A Role for the SmpB-SsrA system in Yersinia pseudotuberculosis pathogenesis. PLoS Pathog. 2: e6. http://dx.doi.org/10.1371/journal.ppat.0020006

Shen PS, Park J, Qin Y, Li X, et al. (2015). Protein synthesis. Rqc2p and 60S ribosomal subunits mediate mRNAindependent elongation of nascent chains. Science 347: 75-78. http://dx.doi.org/10.1126/science.1259724

Shpanchenko OV, Golovin AV, Bugaeva EY, Isaksson LA, et al. (2010). Structural aspects of trans-translation. IUBMB Life 62: 120-124.

Skarstad K, Boye E and Steen HB (1986). Timing of initiation of chromosome replication in individual Escherichia coli cells. EMBO J. 5: 1711-1717.

Soncini FC, Véscovi EG and Groisman EA (1995). Transcriptional autoregulation of the Salmonella typhimurium phoPQ operon. J. Bacteriol. 177: 4364-4371.

Tenson T and Ehrenberg M (2002). Regulatory nascent peptides in the ribosomal tunnel. Cell 108: 591-594. http://dx.doi. org/10.1016/S0092-8674(02)00669-4

Tyagi JS and Kinger AK (1992). Identification of the 10Sa RNA structural gene of Mycobacterium tuberculosis. Nucleic Acids Res. 20: 138.http://dx.doi.org/10.1093/nar/20.1.138

Withers HL and Bernander R (1998). Characterization of dnaC2 and dnaC28 mutants by flow cytometry. J. Bacteriol. 180: 1624-1631.

Yao Y, Wunier W and Morigen M (2015). Absence of the BaeR protein leads to the early initiation of DNA replication in Escherichia coli. Genet. Mol. Res. 14: 16888-16895. http://dx.doi.org/10.4238/2015.December.14.16

Genetics and Molecular Research 15 (3): gmr.15038407 